\title{
Bilateral but not unilateral tubal obstruction is associated with positive chlamydia serology
}

\author{
Fabiana C Approbato ${ }^{1}$, Mário S Approbato ${ }^{1}$, Mônica C S Maia ${ }^{1}$, Yanna A R de Lima ${ }^{1}$, Maria A Barbosa ${ }^{2}$, Beatriz B \\ do $C$ Benetti $^{3}$
}

\author{
${ }^{1}$ Brazil Human Reproduction Laboratory. Obstetric and Gynecology Dept. Federal University of Goias State, \\ Brazil \\ ${ }^{2}$ Nursing School. Federal University of Goias State, Brazil \\ ${ }^{3}$ Nutrition School. Federal University of Goias State, Brazil
}

\begin{abstract}
Objective: To assess the association between positive Chlamydia trachomatis (C. trachomatis) serology and unilateral or bilateral tubal obstruction.

Methods: This was a cross sectional study that evaluated the association of positive $C$. trachomatis serology (Immunofluorescence Indirect Serology, IIF or Enzyme Immune Essay, EIE), in two infertile groups: A. 243 patients (27 with unilateral obstruction and 216 without it). B. 247 patients ( 31 with bilateral obstruction and 216 without it). The exclusion criteria were tubal ligation (tubectomy) and tubal surgery. The statistical test (SPSS 17.0) was the Chi-Square with a $p=5 \%$. Tubal obstruction was diagnosed through hysterosalpingography (HSG).

Results: The mean age of the patients without obstruction was 33.6 years, SD 4.9. The mean age of the patients with unilateral obstruction was 33.7 years SD 4.9. The mean age of the patients with bilateral obstruction was 33.6 years, SD 4.9. There was no statistically significant difference between the age groups. In group A (unilateral obstruction versus serology) the Chi-Square was 0.02 $(p=$ n.s. $)$ and the Attributable Risk $(A R)=0.7 \%$. In Group $B$ (bilateral obstruction versus serology) the Chi-Square test was $9.87(p<0.005)$ and the $\mathrm{AR}=14.8 \%$.

Conclusion: : This study found a strong and statistically significant association between bilateral tubal obstruction and $C$. trachomatis positive serology. The power of the test was $86 \%$. There was no association between unilateral obstruction and positive serology.
\end{abstract}

Keywords: tubal obstruction, Chlamydia trachomatis, C. trachomatis, tubal patency, infertility

\section{INTRODUCTION}

Chlamydia trachomatis infection is one of the most common sexually transmitted bacterial diseases, particularly in women (WHO, 2001). In 2009, a total of 1,244,180 Chlamydia infections was reported to the Centers for Disease Control (CDC) in 50 states and the District of Columbia, an increase of $2.8 \%$ when compared with 2008 (CDC, 2010). Even in developed countries the prevalence of $C$. trachomatis seems to be increasing. In Sweden, the incidence of Chlamydia infection increased from 171.7 to 406.2 cases per 100,000 between 1998 and 2009 (Sylvan \& Christenson, 2008; Christenson \& Sylvan, 2011).

The risk ratio of infection-induced reproductive diseases can be underestimated because up to $70 \%-80 \%$ of acute Chlamydia infections in women are asymptomatic or subclinical, and are not diagnosed or treated (Peipert,
2003). According to the World Health Organization, $10 \%$ $40 \%$ women with untreated or repeated infections develop symptomatic pelvic inflammatory disease (WHO, 2016), which results in scarring and fibrosis of the Fallopian tubes (Hillis et al., 1997) and can lead to ectopic pregnancy (Chow et al., 1990). Moreover, 30\%-40\% of cases of female infertility are caused by postinfectious tubal damage resulting in hydrosalpinx (Brunham \& Rey-Ladino, 2005; WHO, 2016). Chlamydia infection treatment does not always prevent progressive tubal damage (Brunham \& Rey-Ladino, 2005).

C. trachomatis infection has been on the rise worldwide and frequently causes tubal damage, often irreparable, of difficult management, limiting the reproductive capacity of women (WHO, 2001). Due to its serious consequences, $C$. trachomatis antibody testing is part of the infertility workup suggested by the Dutch Society of Obstetrics and Gynecology (Dobekousen et al., 1994).

The prevalence of tubal pathology in female infertility varies depending on the author. Some published that it is estimated that $30 \%$ of infertile females have tubal pathology (Evers, 2002; Brandes et al., 2010). Dobekousen et al. (1994) found a total of $14 \%$ of tubal factor in female infertility. Between 10 and $15 \%$ of all women seeking In Vitro Fertilization in the United Kingdom are due to tubal infertility (HFEA, 2016).

Several hypotheses about tubal implantation have been proposed, including inhibition of ciliary beating and muscle contraction, stimulation of tubal secretion, and early embryo-tubal cell interaction (Shah et al., 2005). It has been speculated that an antibody response to the Chlamydia 60-kDa heat shocks the protein (hsp-60) and causes a tubal inflammatory response, leading to tubal blockage or a predisposition to tubal implantation (van Mourik et al., 2009; Daponte et al., 2012). There is evidence that the steroid hormones $17 \beta$-estradiol $\left(E_{2}\right)$ and progesterone $\left(P_{4}\right)$ increase susceptibility to Chlamydia infection and modulate inflammation in epithelial cells (Amirshahi et al., 2011; Hall et al., 2011).

The tubal secretory function is incompletely characterized, but epithelial cell secretions are known to affect gamete fertilization and early human embryo development. The makeup and volume of Fallopian tube fluid depend on physiological and pathophysiological conditions (Avilés et al., 2010). One consequence of tubal infection in mice is hydrosalpinx, as defined by tubal dilatation and abnormal fluid buildup (Shah et al., 2005). Hydrosalpinx has adverse effects on ongoing pregnancies and female fertility, perhaps by reducing endometrial receptivity (Cakmak \& Taylor, 2011). Since successful intrauterine implantation requires a sustainable microenvironment (Jabbour et al., 2006), an important question is how Chlamydia-induced 
hydrosalpinx formation changes the local microenvironment and consequently triggers tubal implantation in women.

We did not find publications investigating whether or not unilateral tubal obstructions are associated with seropositivity for $C$. trachomatis seropositivity. It was the goal of this paper to evaluate if seropositivity also relates to unilateral tubal obstruction.

\section{MATERIALS AND METHODS}

This was a cross-sectional study that evaluated the association of positive Chlamydia serology (Immunofluorescence Indirect Serology, IFI or Enzyme Immune Essay, EIE), in two infertile groups: Group A: 243 patients (27 with unilateral and 216 without tubal obstruction). Group B: 247 patients ( 31 with bilateral and 216 without tubal obstruction). The exclusion criteria were tubal ligation (tubectomy) and tubal surgery. The statistics assessment package used was the SPSS 17.0. The Chi-Square test yielded $p=5 \%$. Tubal obstruction diagnosed was made by hysterosalpingography, which is a test part of the workup of infertile couples, a minimally invasive method of evaluating tubal patency and is performed as the first line approach for assessing tubal pathology (Foroozanfard \& Sadat, 2013).

\section{RESULTS}

The mean age of the patients without obstruction was 33.6 years, SD 4.9. The mean age of the patients with unilateral obstruction was 33.7 years, SD 4.9. The mean age of the patients with bilateral obstruction was 33.6 years, SD 4.9. There is no statistical difference between age groups. In group A (unilateral obstruction versus serology) the Chi-Square was 0.02 ( $p=$ n.s.), and the Attributable Risk $(A R)=0.7 \%$ (Figure 1 ). In Group B (bilateral obstruction versus serology) the Chi-Square test was 9.87 $(p<0.005)$, with $\mathrm{AR}=14.8 \%$ (Figure 2 ).

\section{DISCUSSION}

HSG is used worldwide to evaluate tubal patency. It is a simple method for assessing female sterility, it is a less ex-

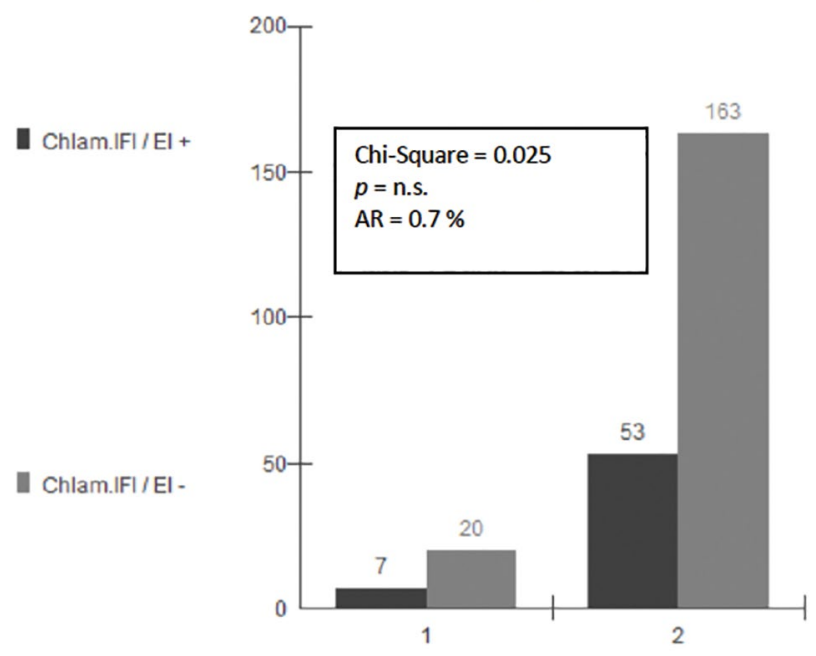

Figure 1. Unilateral Tubal Obstruction and Chlamydia Seropositivity. Human IVF Laboratory. Federal University of Goiás State, Brazil, 2018. 1 = Obstruction Yes. 2 = Obstruction No. AR = Attributable Risk. IFI = Indirect Immunofluorescence. EI = Enzyme immunoassay.

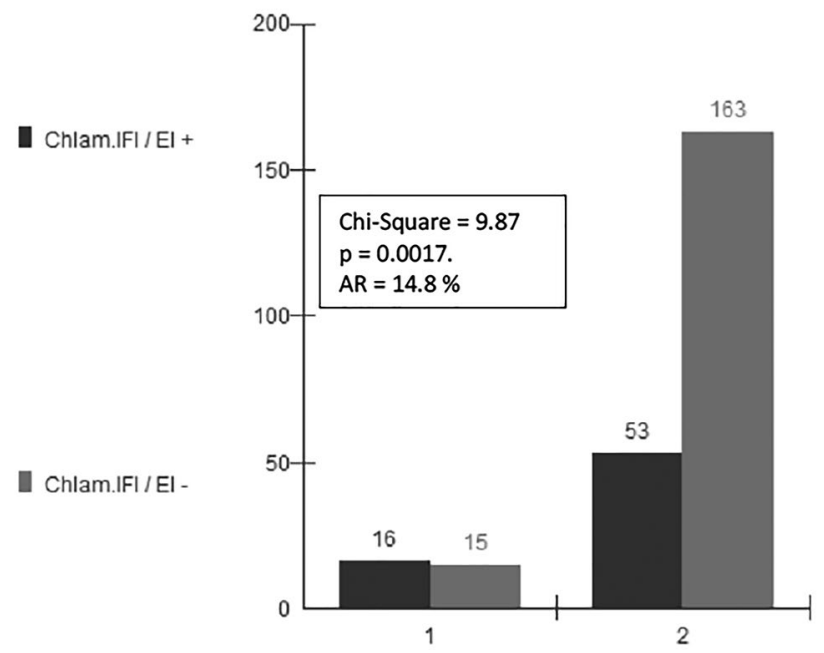

Figure 2. Bilateral Tubal Obstruction and Chlamydia Seropositivity. Human IVF Laboratory. Federal University of Goiás State, Brazil, 2018. 1 = Obstruction Yes. 2 = Obstruction No. AR = Attributable Risk. IFI = Indirect Immunofluorescence. EI = Enzyme immunoassay

pensive and elementary method to evaluate tubal pathologies, and can identify some congenital uterine anomalies. The advantage of laparoscopy is that it can identify some other pelvic abnormalities which may be the cause of infertility that cannot be detected by HSG, such as endometriosis, adhesions and tuberculosis. However, one limitation of HSG is that the interpretation of the images depends on the experience and skill of the radiologists involved (Foroozanfard \& Sadat, 2013).

In a research, HSG was compared with laparoscopy, and the results showed that sensitivity was $65 \%$ for tubal patency, but it increases the achievement of spontaneous pregnancy by three fold (Torre et al., 2010). Other authors in a cohort study investigated eighty-two infertile cases to compare tuboperitoneal factors by HSG and laparoscopy, and the results showed that pathological findings were seen in $45.1 \%$ by HSG and $65.85 \%$ by laparoscopy. The sensitivity and specificity of HSG were $63 \%$ and $89.3 \%$, respectively, and the positive predictive value was $92 \%$, with a $55 \%$ negative predictive value, and an accuracy ratio was $72 \%$ (Sakar et al., 2008).

In a series of 360 infertile women, an initial hysterosalpingography study suggested an incidence of unilateral proximal tubal obstruction in 18 , and bilateral obstruction in 22 women. When the HSG was repeated one month later, the unilateral obstruction persisted in $12(3.3 \%)$ and the bilateral obstruction in $9(1.1 \%)$ women (Dessole et al., 2000).

In the year 2018, the prevalence of tubal obstruction in a sample of 292 infertile patients seen at the Humana Laboratory of the Federal University of Goiás State had the following distribution: Uni or bilateral obstruction in $21.9 \%$, bilateral in $10.9 \%$ and unilateral in $9.9 \%$. Serology (Immunofluorescence Indirect Serology, IIF or Enzyme Immune Assay, EIA) was positive for C. trachomatis in $27.1 \%$. PCR was positive in $0.94 \%$ of patients. Steiner et al. (2015) published a study using a newer anti-Ct (anti Chlamydia trachomatis) assay developed by Geisler et al. (2012) that is, an elementary body-based ELISA that has been shown to have higher sensitivity and specificity than prior assays. Steiner et al. (2015) found that $19 \%$ of the women in their sample were seropositive for anti-C. trachomatis IgG3. Approbato (2012) found in a Master of Science (MS) graduate 
paper that $0.83 \%$ (120 patients) were PCR positive for $C$. trachomatis. In this same publication, this author found $36.5 \%$ of seropositivity in IIF or EIA.

Even in the presence of tubal patency, anti-C. trachomatis IgG3 seropositivity is associated with a lower likelihood of pregnancy and increased pregnancy complications. Steiner et al. (2015) found that positive anti-C. trachomatis diagnosis, using the new IgG3 test, women have as high as 3 times the risk of having an ectopic pregnancy. These same authors found that Anti-C. trachomatis IgG3 seropositive women were significantly less likely to conceive (risk ratio [RR] $0.65,95 \%$ confidence interval [CI] $0.52-0.83$ ) or to have a live birth (RR $0.59,95 \% \mathrm{CI}$ $0.43-0.80$ ). To date, the specificity of the anti-Ct assay due to cross-reactivity with other Chlamydia strains has limited its clinical utility as a predictive test. Standard methodologies used to assess Fallopian tubes, assess the patency but not function (Feinberg, 2015). The utility of the improved detection method for anti-Ct antibody should be met with cautious, because tubal patency does not imply tubal function. Seropositive patients should not be driven immediately for IVF treatments. But, it may be reasonable, in the setting of positive anti-Ct antibodies, to limit the number of ovulation induction cycles and pursue IVF if not pregnant after three cycles (Feinberg, 2015).

Titration of anti-C. trachomatis antibodies has been used to track tubal obstruction and pathologies. Rodgers et al. (2011) published that infertile women with laparoscopically identified tubal pathologies developed significantly higher titers of anti-C. trachomatis antibodies. Many publications (Musich \& Behrman, 1983; Serafini \& Batzofin, 1989; Healy et al., 1994) described a prevalence of tubal obstruction and others pelvic diseases from $25 \%$ to $35 \%$ in patients with infertility, mainly by C. trachomatis. Nevertheless, there's no evaluation if these tubal obstructions were uni or bilateral. This paper is one of the first to show that unilateral obstruction is not related to seropositivity for $C$. trachomatis. It may be that in these cases, tubal spasms or false positivity are the probable causes. It seems that when there is an infection by this sexually transmitted disease, it affects both female tubes simultaneously. Other studies should be carried out to confirm these finds.

\section{CONCLUSION}

This study found a strong and statistically significant association between bilateral tubal obstruction and Chlamydia positive serology. The power of the test was $86 \%$. There was not an association between unilateral obstruction and positive serology. This is one of the first published studies to show this.

\section{ACKNOWLEDGEMENT}

The authors would like to thank the Human Reproduction Laboratory HC/GO to support this study.

This study was partially financed by the Coordenação de Aperfeiçoamento de Pessoal de Nível Superior - Brasil (CAPES) - Finance Code 001.

\section{CONFLICTS OF INTEREST}

The authors have no potential conflicts of interest, whether political, economic, of resources for research execution or intellectual property to declare.

\section{Correponding Author:}

Fabiana C Approbato

Human Reproduction Laboratory/LabRep HC/GO

Obstetric and Gynecology Dept.

Federal University of Goias State, Goias - Brazil.

E-mail: fabianapprobato@gmail.com

\section{REFERENCES}

Amirshahi A, Wan C, Beagley K, Latter J, Symonds I, Timms P. Modulation of the Chlamydia trachomatis in vitro transcriptome response by the sex hormones estradiol and progesterone. BMC Microbiol. 2011;11:150. PMID: 21702997 DOI: $10.1186 / 1471-2180-11-150$

Approbato FC. Prevalência da Chlamydia trachomatis pela técnica de reação em cadeia da polimerase (PCR) em mulheres inférteis [Dissertation]. Post Graduation in Health Science. Goiânia: Federal University of Goias State, Brazil; 2012.

Avilés $M$, Gutiérrez-Adán A, Coy P. Oviductal secretions: will they be key factors for the future ARTs? Mol Hum Reprod. 2010;16:896-906. PMID: 20584881 DOI: 10.1093/ molehr/gaq056

Brandes M, Hamilton CJ, De Bruin JP, Nelen WL, Kremer JA. The relative contribution of IVF to the total ongoing pregnancy rate in a subfertile cohort. Hum Reprod. 2010;25:118-26. PMID: 19855108 DOI: 10.1093/ humrep/dep341

Brunham RC, Rey-Ladino J. Immunology of Chlamydia infection: implications for a Chlamydia trachomatis vaccine. Nat Rev Immunol. 2005;5:149-61. PMID: 15688042 DOI: $10.1038 /$ nri1551

Cakmak H, Taylor HS. Implantation failure: molecular mechanisms and clinical treatment. Hum Reprod Update. 2011;17:242-53. PMID: 20729534 DOI: 10.1093/ humupd/dmq037

CDC - Centers for Disease Control and Prevention. U.S. Department of Health and Human Services, National Center for HIV/AIDS, Viral Hepatitis, STD, and TB prevention. Division of STD Prevention. Sexually transmitted disease surveillance 2009. Atlanta: CDC; 2010.

Chow JM, Yonekura ML, Richwald GA, Greenland S, Sweet $\mathrm{RL}$, Schachter J. The association between Chlamydia trachomatis and ectopic pregnancy. A matched-pair, case-control study. JAMA. 1990;263:3164-7. PMID: 2348526 DOI: 10.1001/Jama.1990.03440230060033

Christenson B, Sylvan SPE. Changing epidemiology of sexually transmitted infections: call for new strategies against the increase in Chlamydia infection in Sweden. Open Infect Dis J. $2011 ; 5: 120-6$. DOI: $10.2174 / 1874279301105010120$

Daponte A, Pournaras S, Deligeoroglou E, Skentou H, Messinis IE. Serum interleukin- $1 \beta$, interleukin- 8 and anti-heat shock 60 Chlamydia trachomatis antibodies as markers of ectopic pregnancy. J Reprod Immunol. 2012;93:102-8. PMID: 22386127 DOI: $10.1016 /$ j.jri.2012.01.003

Dessole S, Meloni GB, Capobianco G, Manzoni MA, Ambrosini G, Canalis GC. A second hysterosalpingography reduces the use of selective technique for treatment of a proximal tubal obstruction. Fertil Steril. 2000;73:1037-9. PMID: 10785234 DOI: 10.1016/S0015-0282(00)00415-5

Dobekousen YA, Evers JL, Land JA, Stals FS. Chlamydia trachomatis antibody testing is more accurate than hysterosalpingography in predicting tubal factor infertility. Fertil Steril. 1994;61:833-7. PMID: 8174718 DOI: 10.1016/ S0015-0282(16)56692-8 
Evers JL. Female subfertility, Lancet 2002:360:151-9. PMID: 12126838 . DOI: 10.1016/S0140-6736(02)09417-5

Feinberg EC. Expanding the scope of the basic infertility work-up. Fertil Steril. 2015;104:1379. PMID: 26453268 DOI: $10.1016 /$ j.fertnstert.2015.09.010

Foroozanfard F, Sadat Z. Diagnostic value of hysterosalpingography and laparoscopy for tubal patency in infertile women. Nurs Midwifery Stud. 2013;2:188-92. PMID: 25414857

Geisler WM, Morrison SG, Doemland ML, Iqbal SM, Su J, Mancevski A, Hook EW 3rd, Morrison RP. Immunoglobulin-specific responses to Chlamydia elementary bodies in individuals with and at risk for genital chlamydial infections. J Infect Dis. 2012;206:1836-43. PMID: 23045619 DOI: $10.1093 /$ infdis/jis621

Hall JV, Schell M, Dessus-Babus S, Moore CG, Whittimore JD, Sal M, Dill BD, Wyrick PB. The multifaceted role of oestrogen in enhancing Chlamydia trachomatis infection in polarized human endometrial epithelial cells. Cell Microbiol. 2011;13:1183-99. PMID: 21615662 DOI: 10.1111/j.14625822.2011.01608.x

Healy DL, Trounson AO, Andersen AN. Female infertility: causes and treatment. Lancet. 1994;343:1539-44. PMID: 7911874 DOI: 10.1016/S0140-6736(94)92941-6

HFEA- Human Fertilization and Embryology Authority. Fertility Treatment. 2014: Trends and Figures. London: HFEA; 2016.

Hillis SD, Owens LM, Marchbanks PA, Amsterdam LF, Mac Kenzie WR. Recurrent chlamydial infections increase the risks of hospitalization for ectopic pregnancy and pelvic inflammatory disease. Am J Obstet Gynecol. 1997;176:1037. PMID: 9024098 DOI: $10.1016 /$ S0002-9378(97)80020-8

Jabbour HN, Kelly RW, Fraser HM, Critchley HO. Endocrine regulation of menstruation. Endocr Rev. 2006;27:17-46. PMID: 16160098 DOI: 10.1210/er.2004-0021

Musich JR, Behrman SJ. Surgical management of tubal obstruction at the uterotubal junction. Fertil Steril. 1983;40:423-41. PMID: 6617902 DOI: 10.1016/S00150282(16)47349-8

Peipert JF. Clinical practice. Genital chlamydial infections. N Engl J Med. 2003;349:2424-30. PMID: 14681509. DOI: 10.1056/NEJMcp030542
Rodgers AK, Budrys NM, Gong S, Wang J, Holden A, Schenken RS, Zhong G. Genome-wide identification of Chlamydia trachomatis antigens associated with tubal factor infertility. Fertil Steril. 2011;96:715-21. PMID: 21742324 DOI: 10.1016/j.fertnstert.2011.06.021

Sakar MN, Gul T, Atay AE, Celik Y. Comparison of hysterosalpingography and laparoscopy in the evaluation of infertile women. Saudi Med J. 2008;29:1315-8. PMID: 18813419

Serafini $P$, Batzofin J. Diagnosis of female infertility. A comprehensive approach. J Reprod Med. 1989;34:29-40. PMID: 2649667

Shah AA, Schripsema JH, Imtiaz MT, Sigar IM, Kasimos J, Matos PG, Inouye S, Ramsey $\mathrm{KH}$. Histopathologic changes related to fibrotic oviduct occlusion after genital tract infection of mice with Chlamydia muridarum. Sex Transm Dis. 2005;32:49-56. PMID: 15614121 DOI: $10.1097 / 01$. olq.0000148299.14513.11

Steiner AZ, Diamond MP, Legro RS, Schlaff WD, Barnhart KT, Casson PR, Christman GM, Alvero R, Hansen KR, Geisler WM, Thomas T, Santoro N, Zhang $\mathrm{H}$, Eisenberg EReproductive Medicine Network ;. Chlamydia trachomatis immunoglobulin G3 seropositivity is a predictor of reproductive outcomes in infertile women with patent Fallopian tubes. Fertil Steril. 2015;104:1522-6. PMID: 26413816 DOI: $10.1016 /$ j.fertnstert.2015.08.022

Sylvan S, Christenson B. Increase in Chlamydia trachomatis infection in Sweden: time for new strategies. Arch Sex Behav. 2008;37:362-4. PMID: 18058014 DOI: 10.1007/ s10508-007-9283-z

Torre A, Pouly JL, Wainer B. Anatomic evaluation of the female of the infertile couple. J Gynecol Obstet Biol Reprod (Paris). 2010;39:S34-44. PMID: 21185484 DOI: 10.1016/ S0368-2315(10)70029-6

van Mourik MS, Macklon NS, Heijnen CJ. Embryonic implantation: cytokines, adhesion molecules, and immune cells in establishing an implantation environment. J Leukoc Biol. 2009;85:4-19. PMID: 18784344 DOI: 10.1189/ jlb.0708395

WHO - World Health Organization. Global prevalence and incidence of selected curable sexually transmitted infections: overview and estimates. Geneva: WHO; 2001. Available at: http://www.who.int/reproductivehealth/publications/rtis/HIV_AIDS_2001_2/en/. Accessed 2018 Sep 30.

WHO - World Health Organization. Sexually transmitted infections, Fact sheet No.110. Geneva: WHO; 2016. Available at: http://www.who.int/news-room/fact-sheets/detail/sexually-transmitted-infections-(stis). Accessed 2018 Sep 30. 